\title{
Function of Genes Encoding Acyl-CoA Synthetase and Enoyl-CoA Hydratase for Host-Selective ACT-Toxin Biosynthesis in the Tangerine Pathotype of Alternaria alternata
}

\author{
Y. Miyamoto, Y. Ishii, A. Honda, A. Masunaka, T. Tsuge, M. Yamamoto, K. Ohtani, \\ T. Fukumoto, K. Gomi, T. L. Peever, and K. Akimitsu
}

First, second, third, fourth, seventh, eighth, ninth, and eleventh authors: United Graduate School and Faculty of Agriculture, Kagawa University, Miki, Kagawa 761-0795 Japan; fifth author: Graduate School of Bioagricultural Sciences, Nagoya University, Nagoya 4648601 Japan; sixth author: Faculty of Agriculture, Okayama University, Okayama 700-8530 Japan; and tenth author: Department of Plant Pathology, Washington State University, Pullman 99164-6430. Accepted for publication 13 October 2008.

\begin{abstract}
Miyamoto, Y., Ishii, Y., Honda, A., Masunaka, A., Tsuge, T., Yamamoto, M., Ohtani, K., Fukumoto, T., Gomi, K., Peever, T. L., and Akimitsu, K. 2009. Function of genes encoding acyl-CoA synthetase and enoyl-CoA hydratase for host-selective ACT-toxin biosynthesis in the tangerine pathotype of Alternaria alternata. Phytopathology 99:369-377.

The tangerine pathotype of Alternaria alternata produces host-selective ACT-toxin and causes Alternaria brown spot disease. Sequence analysis of a genomic cosmid clone identified a part of the ACTT gene cluster and implicated two genes, ACTT5 encoding an acyl-CoA synthetase and ACTT6 encoding an enoyl-CoA hydratase, in the biosynthesis of ACTtoxin. Genomic Southern blots demonstrated that both genes were present in tangerine pathotype isolates producing ACT-toxin and also in Japanese pear pathotype isolates producing AK-toxin and strawberry pathotype iso-
\end{abstract}

ABSTRACT lates producing AF-toxin. ACT-, AK-, and AF-toxins from these three pathotypes share a common 9,10-epoxy-8-hydroxy-9-methyl-decatrienoic acid moiety. Targeted gene disruption of two copies of ACTT5 significantly reduced ACT-toxin production and virulence. Targeted gene disruption of two copies of ACTT6 led to complete loss of ACT-toxin production and pathogenicity and a putative decatrienoic acid intermediate in ACT-toxin biosynthesis accumulated in mycelial mats. These results indicate that ACTT5 and ACTT6 are essential genes in ACT-toxin biosynthesis in the tangerine pathotype of $A$. alternata and both are required for full virulence of this fungus.

Additional keywords: citrus, host-specific toxin, toxin biosynthesis gene cluster.
Seven strains of Alternaria alternata (Fr.) Keissl. are known to produce host-selective toxins (HST) that are selectively toxic to certain cultivars of host plants. Alternaria HSTs are low-molecular-weight, secondary metabolites with toxicity toward distinct plant genotypes, and have the same specificity as infection by the toxin-producing pathogen $(24,30,34-36)$. These HST-producing strains are defined as seven distinct pathotypes $(16,24)$ to reflect their morphological similarity. Pathotypes can be easily distinguished based on host range. The chemical structures of HSTs from six pathotypes of $A$. alternata have been elucidated (16), and HST biosynthetic genes were recently cloned from the Japanese pear pathotype, strawberry pathotype, tangerine pathotype, and apple pathotype of $A$. alternata (4-6,9,10,18-20,27,31,32).

The tangerine pathotype of $A$. alternata causes Alternaria brown spot disease, which affects many tangerines, mandarins, and their hybrids, and pathogenicity is dependent on the production of ACT-toxin $(2,16,17)$. The structure of ACT-toxin is related to AK- and AF-toxins, which are the HSTs produced by the Japanese pear and strawberry pathotypes of A. alternata $(15,21$, $22)$. These toxins share a common 9,10-epoxy-8-hydroxy-9methyl-decatrienoic acid moiety (Fig. 1) $(15,21,22)$. Homologues

Corresponding author: K. Akimitsu; E-mail address: kazuya@ag.kagawa-u.ac.jp

First three authors contributed equally to this work. Accession numbers from DDBJ/GenBank of pcCL4-1, ACTT5, and ACTT6 are AB176941, AB444613, and AB444614, respectively.

doi:10.1094/PHYTO-99-4-0369

(C) 2009 The American Phytopathological Society of three genes responsible for biosynthesis of the decatrienoic acid moiety in the Japanese pear pathotype (AKT1, AKT2, and $A K T T R)$ are also found in the tangerine and strawberry pathotypes (18-20,31,32). Using AKTR (32) as a heterologous probe, we have identified a contiguous 33,974-bp region of chromosomal DNA (accession number AB176941) from a cosmid clone of the tangerine pathotype SH20. The 33,974-bp region contained five genes, and we report here the distributions and role in pathogenicity and virulence of two of these genes encoding a putative acyl-CoA synthetase (1,883 bp) designated ACTT5 and a putative enoyl-CoA hydratase (897 bp) designated ACTT6.

\section{MATERIALS AND METHODS}

Fungal strains and plants. Young leaves (midrib length 2 to 4 $\mathrm{cm}$ ) were obtained from citrus cv. Iyokan tangor (Citrus iyo hort. Ex Tanaka), grown in the greenhouse, and used for inoculation and toxin sensitivity assays as described previously $(19,20)$. Iyokan is susceptible to the tangerine pathotype of A. alternata and sensitive to ACT-toxin (14). Strains of A. alternata tangerine pathotype were sampled from leaf lesions of Minneola tangelo (C. reticulata Blanco $\times C$. paradisi Macf.) in Florida for a study of the population structure and host specificity of the Alternaria brown spot pathogen (18-20,25). Tangerine pathotype isolates SH11, 12, 14, 15, 18, 19, 20, 21, and EV10, 13, 14, and 17 and rough lemon pathotype isolates $\mathrm{HC} 1$ and 8 were isolated from leaf lesions on both hosts in central Florida $(18,19,25)$. Tangerine pathotype strain $\mathrm{SH} 20$ has been used previously as a reference strain for the brown spot pathogen (18-20). Isolate BC3-5-1- 
OS2A, which is a dual pathotype strain producing both ACT-toxin and ACR-toxin (18), was isolated from a rough lemon leaf lesion in central Florida. In addition, laboratory stocks (9) of Japanese pear pathotype isolates G31 and G90-A2, strawberry pathotype isolates NAF-3 and NAF-8, tomato pathotype isolates 91080804 and AL-4, apple pathotype isolates AM-1 and O-159, and tobacco pathotype isolates No. 122-2 and AT-204 were used in this study. Isolate $\mathrm{HC} 14$ was a nonpathogenic strain of A. alternata sampled from rough lemon leaves $(19,25)$, and another nonpathogenic $A$. alternata isolate O-94 was obtained from H. Otani, Tottori University, Japan. An additional 16 tangerine pathotype and nonpathotype strains were sampled worldwide from tangerines and mandarins (C. reticulata Blanco) or tangerine $\times$ grapefruit hybrids (C. reticulata $\times$ C. paradisi Macf.) in Israel, South Africa, Turkey, Australia, and Colombia (26). All isolates including transformants of isolate SH20 were stored in $25 \%$ ( vol/vol) glycerol at $-85^{\circ} \mathrm{C}$, and cultures were initiated from the stocks for each experiment by growth on V8 juice agar or potato dextrose agar (PDA) plates.

Nucleic acid manipulations. Extraction of genomic DNA and total RNA, genomic polymerase chain reaction (PCR), reverse transcription (RT)-PCR and Southern blot hybridization using DIG-PCR-labeled probes were carried out as previously described $(7,11,12,18-20)$. Restriction enzyme digestion of genomic DNA $(5 \mu \mathrm{g})$, agarose gel electrophoresis, and capillary transfer were conducted under standard conditions (28). Transcripts of ACTT5 or ACTT6 were amplified with or without addition of reverse transcriptase (Takara, Shiga, Japan) by RT-PCR using the following primer sets: ACTT5S1F1 (5'-GTGTAGCAGCGGGACG-3') and ACTT5S1R1 (5'-CTACCGTTGGACCGCG-3') for ACTT5, ACTT6F1 (5'-TTTGATGTCGCATTCG-3') and ACTT6R1 (5'CAATATGCCGGCACTC-3') for ACTT6, and actinFor (5'-AGATGACACAGATTGTTTTCGAGACC-3') and actinRev (5'-AGTTGAAAGTGGTGACGTGGATACC-3') for actin gene (actl of $A$. alternata) (AY748985), respectively. RT-PCR products for ACTT5 were transferred to Hybond- $\mathrm{N}^{+}$membrane using standard

\section{ACT-toxin}

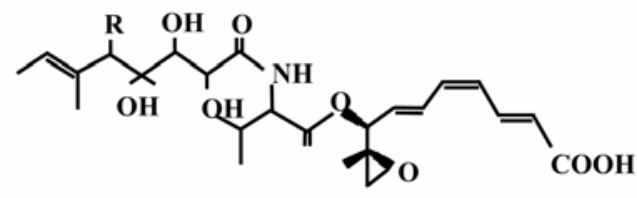

ACT-toxin I: $\mathrm{R}=\mathrm{OH}$

ACT-toxin II: $\mathrm{R}=\mathrm{H}$

AK-toxin

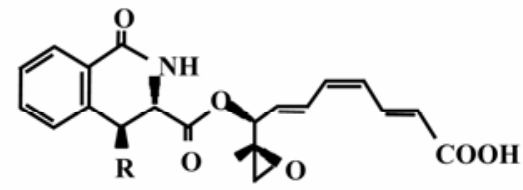

AK-toxin I: $\mathrm{R}=\mathrm{CH}_{3}$ AK-toxin II: $\mathrm{R}=\mathrm{H}$

\section{AF-toxin}

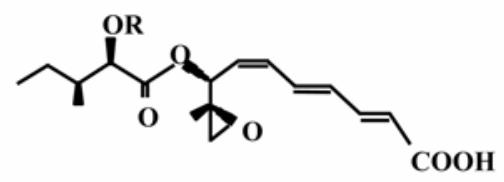

AF-toxin I: $\mathrm{R}=\mathrm{COCH}(\mathrm{OH}) \mathrm{C}\left(\mathrm{CH}_{3}\right)_{2} \mathrm{OH}$

AF-toxin II: $\mathbf{R}=\mathbf{H}$

AF-toxin III: $\mathrm{R}=\mathrm{COCH}(\mathrm{OH}) \mathrm{CH}\left(\mathrm{CH}_{3}\right)_{2}$

Fig. 1. Chemical structures of ACT-, AK-, and AF-toxins produced by the tangerine pathotype, Japanese pear pathotype, and strawberry pathotype of Alternaria alternata, respectively $(15,21,22)$. methods (28) and detected with DIG-labeled PCR amplicons of ACTT5 (ACTT5 probe) or ACTT6 (ACTT6 probe) prepared with same primer sets used for RT-PCR and cosmid DNA of pcCL4-1 (AB176941) as the template by the method described previously (7,11,12,18-20). A probe for the hygromycin resistance gene $\mathrm{Hph}$ was prepared using a primer set of hphF1 (5'-CTGAACTCACCGCGACGT-3') and hphR1 (5'-CCTTTGCCCTCGGACG-3') (3) in the pSH75 vector. This vector contains the $h p h$ cassette for hygromycin resistance as the selective marker and was labeled with same procedures as described for the ACTT5 and ACTT6 probes.

Sequencing was performed by the dideoxy chain termination method (29) using an ABI PRISM Dye Termination Cycle Sequencing Ready Reaction Kit (Applied Biosystems, Foster City, CA) and an automated fluorescent DNA sequencer (Model 310, Applied Biosystems). Sequence identities were estimated using FASTA searches at the DNA Data Bank of Japan.

Plasmid vector constructs and fungal transformation. The gene replacement vector pPCR-script::ACTT5::hph was constructed with partial ACTT5 sequences amplified by PCR with the primer set ACTT5F1 (5'-GACTCAGAGCACCGGA-3') and ACTT5R1 (5'-ACTGCTCTGTCGCAGC-3') using cosmid DNA of pcCL4-1 (AB176941) as the template. The partial ACTT5 sequence amplified by PCR was first subcloned into the EcoRV site of subcloning vector pT7Blue-2 (Novagen, Madison, WI) following digestion with EcoRI and SalI, and was resubcloned at the same enzyme sites (EcoRI and SalI) of pCR-script Amp $\mathrm{SK}(+)$ (Stratagene, La Jolla, CA). The vector was then digested with HindIII and EcoRV, which cut in the middle of the ACTT5 ORF, and ligated with a $h p h$ cassette from the fungal transformation vector pSH75 $(3,7,13)$ excised with HindIII and EcoRV, to construct pPCR-script::ACTT5::hph for the first disruption of ACTT5. The vector was digested with NotI and KpnI, and linearized before transformation of isolate $\mathrm{SH} 20$. For the second disruption of ACTT5, a blunt-ended PCR fragment amplified from ACTT5 using the primer set ACTT5S1F1 and ACTT5R2EcoRI (5'-CGGAATTCCGATTGGATGCCCCGTAC-3') with cosmid DNA of pcCL4-1 (AB176941) as the template, was subcloned at the EcoRV site of fungal transformation vector pII99 carrying an NPTII cassette (23) for geneticin resistance to produce pII99::ACTT5.

The gene replacement vector pSH75::ACTT6 was constructed using two partial sequences of ACTT6 amplified by PCR using cosmid DNA of pcCL4-1 (AB176941) as the template with respective primer sets ACTT6F3BamHI (5'-CGGGATCCCGTCTGCTGGGAGCAGGT-3') and ACTT6R3XhoI (5'-CCGCTCGAGCGGGGTGGTTGGCCAAGAG-3'), and ACTT6F4BglII (5'-GAAGATCTTCAGCAATGCGGTGTGCC-3') and ACTT6R4SmaI (5'-TCCCCCGGGGGAGTCTGGGCTCATTGCC-3'). One of the ACTT6 PCR fragments amplified with the primer set ACTT6F3BamHI and ACTT6R3XhoI was digested with BamHI and XhoI and subcloned into the BamHI and XhoI sites of transformation vector $\mathrm{pSH75.} \mathrm{Another} \mathrm{ACTT6} \mathrm{PCR} \mathrm{fragment}$ amplified with the primer set ACTT6F4BglII and ACTT6R4SmaI was digested with $B g l \mathrm{II}$ and $S m a \mathrm{I}$ and subcloned into the $B g l \mathrm{II}$ and SmaI sites of the vector pSH75 containing the first partial ACTT6 fragment to generate pSH75::ACTT6. This vector was linearized by digestion with HindIII and XhoI before transformation of isolate $\mathrm{SH} 20$. For the second disruption of ACTT6, a blunt-ended ACTT6 PCR fragment amplified using the primer set ACTT6F1 (5'-TTTGATGTCGCATTCG-3') and ACTT6R1 (5'CAATATGCCGGCACTC-3') was subcloned into the EcoRV site of transformation vector pII99 to generate pII99::ACTT6. Vector constructs for disruption of ACTT5 and ACTT6 were confirmed by sequencing.

Protoplast preparation and transformation of isolate SH20 were carried out using methods described previously $(7,8,11,12,20)$. Protoplasts $\left(1 \times 10^{7}\right)$ were transformed with $3 \mu \mathrm{g}$ of each vector. 
Colonies were transferred to PDA plates containing hygromycin $\mathrm{B}(50 \mu \mathrm{g} / \mathrm{ml})$ or geneticin $(200 \mu \mathrm{g} / \mathrm{ml})$ and grown at $24^{\circ} \mathrm{C}$ for 5 to 7 days and single spore cultures were recovered as described previously $(7,8,11,12,20)$.

Detection of plasmid integration, toxin production, and pathogenicity. Integration patterns of transformation vectors were determined using genomic Southern blots and DIG-labeled ACTT5, ACTT6, or $h p h$ probes. Hybridization and detection were conducted as described previously $(7,8,11,12,18-20)$. Production of ACT-toxin and its putative intermediate compound in culture filtrates, spore germination fluid, and mycelial extracts was determined by high-performance liquid chromatography (HPLC), thinlayer chromatography (TLC), and bioassay. A. alternata isolate SH20 and its mutants were grown on PDA for examination of fungal growth and also in $200-\mathrm{ml}$ flasks containing $50 \mathrm{ml}$ of ACtoxin medium $(15,17)$ for 25 to 30 days at $24^{\circ} \mathrm{C}$ for examination of ACT-toxin production in culture filtrates. Culture filtrates were adsorbed to Amberlite XAD2, extracted with methanol, extracted twice with ethyl acetate, and suspended in methanol following purification through a Sep-Pak Column Plus C18 Cartridge (Waters, Milford, MA) following the protocol described previously (18-20) for culture filtrate extract preparation for HPLC analysis. Mycelial mats were lyophilized using the LABCONCO Freeze dry System/Freezone 2.5 (Kansas City, MO) at $-40^{\circ} \mathrm{C}$ $\left(133 \times 10^{-3} \mathrm{Mb}\right)$ overnight. The mycelial mats $(0.5 \mathrm{~g}$ dry weight $)$ were ground under liquid nitrogen with a mortar and pestle until the mycelia became a fine gray powder. The powder was stirred in $200 \mathrm{ml}$ of methanol for $1 \mathrm{~h}$ at $4^{\circ} \mathrm{C}$ and passed through paper filter (Whatman \#4 filter: Maidstone, England) to remove mycelial residue. Extracts were dried and resuspended in $10 \mathrm{ml}$ each of ethyl acetate and $10 \%$ (wt/vol) $\mathrm{NaH}_{2} \mathrm{PO}_{4}$, and the extracted ethyl acetate layer was dried and resuspended in $5 \mathrm{ml}$ of methanol. Methanol extracts were passed through a Sep-Pak Column Plus C18 Cartridge (Waters) and further analyzed by bioassay and HPLC. The method for spore germination fluid preparation was partially modified from the method of Kohmoto et al. (15). Conidia of isolate $\mathrm{SH} 20$ and its mutants were collected from mycelial mats grown in potato dextrose broth (PDB) for 3 weeks, and suspended in water at $1 \times 10^{7}$ spores $/ \mathrm{ml}$. Three milliliters of the spore suspension was placed as droplets $(20 \mu \mathrm{l} / \mathrm{drop})$ in the bottom of plastic $9 \mathrm{~cm}$ petri dishes and incubated covered at $24^{\circ} \mathrm{C}$ for $24 \mathrm{~h}$. After incubation, droplets were pooled in 1.5- $\mathrm{ml}$ microcentrifuge tubes and centrifuged at 14,000 rpm for $10 \mathrm{~min}$ to pellet germinating spores. The supernatant was collected and evaporated with 10 times volume of methanol at $40^{\circ} \mathrm{C}$ under reduced pressure, and the residue was dissolved in $150 \mu \mathrm{l}$ of methanol following purification through a Sep-Pak column Plus C18 Cartridge (Waters) for HPLC analysis.

HPLC analysis of ACT-toxin and a putative intermediate compound in ACT-toxin biosynthesis was carried out on a Model 880-PU HPLC system (Japan Spectroscopic, Tokyo, Japan) with a Develosil ODS-5 column $(4.6 \times 250 \mathrm{~mm}$, NORUMA Chemical, Aichi, Japan) and a gradient solvent system composed of acetonitrile/water/acetic acid (linear gradient from 30:70:1 to 60:40:1, $\mathrm{vol} / \mathrm{vol} / \mathrm{vol}$ ) in $30 \mathrm{~min}$ at a flow rate of $1 \mathrm{ml} / \mathrm{min}$ with peak detection with an absorbance at $290 \mathrm{~nm}(15,18-20)$. Fifty microliters of ethyl acetate extracted samples from either culture filtrates $(50 \mathrm{ml})$ or mycelial mats $(0.5 \mathrm{~g}$ dry weight) was suspended in 1 $\mathrm{ml}$ of methanol, passed through a Sep-Pak column Plus C18 Cartridge (Waters), and injected for HPLC analysis. Samples extracted from spore germination fluids $(3 \mathrm{ml})$ were suspended in $150 \mu \mathrm{l}$ of methanol, passed through Sep-Pak column Plus C18 Cartridge (Waters), and $50 \mu \mathrm{l}$ of the sample was injected for HPLC analysis. For large-scale preparation of the putative ACTtoxin intermediate compound, HPLC of mycelia extracts was carried out using a Megapak SIL $\mathrm{C}_{18} \mathrm{~T}$ preparative column $(10 \times$ $250 \mathrm{~mm}$, Japan Spectroscopic) with acetonitrile/deionized water $(50: 50, \mathrm{vol} / \mathrm{vol})$ solvent system under a flow rate of $3 \mathrm{ml}$ per min with $290 \mathrm{~nm}$ detection. A large peak with a retention time of 25 to $30 \mathrm{~min}$ was collected. The retention time of the collected material was confirmed using a Develosil ODS-5 column $(4.6 \times 250 \mathrm{~mm})$ with acetonitrile/deionized water/acetic acid (30:70:1 to 60:40:1, $\mathrm{vol} / \mathrm{vol}$, gradient in $30 \mathrm{~min}$ ) solvent system under a flow rate of $1 \mathrm{ml}$ per min with $290 \mathrm{~nm}$ detection $(15,18,19)$ and TLC analysis. The collected peak from the large-scale preparation was dried under reduced pressure, resuspended in $1 \mathrm{ml}$ methanol, and $50 \mu \mathrm{l}$ was used for further HPLC analysis for confirmation as well as TLC analysis. Retention time and quantification of ACT-toxin was determined for each HPLC analysis using previously purified ACT-toxin I (15,18-20).

For TLC determination of the putative intermediate compound in ACT-toxin biosynthesis, samples (10 $\mu$ g per lane) were prepared from culture filtrates, mycelial extracts, and HPLC-purified mycelial extracts. Extracts were prepared from wild-type isolate SH20, single copy ACTT6 disruptant 53, or double copy ACTT6 disruptant 53-30 and run on TLC (Merck Silica gel $60 \mathrm{~F}_{254}$, Darmstadt, Germany) using a solvent system of benzene/acetic acid (90:10, vol/vol). Compounds were detected by irradiating plates with UV light at $315 \mathrm{~nm}$ or spraying plates with sulfuric acid/ethanol $(5: 95, \mathrm{vol} / \mathrm{vol})$ following by heating at $180^{\circ} \mathrm{C}$ until spots appeared.

To determine the toxicity to plants of ACT-toxin and the putative intermediate compound in culture filtrates, HPLC fractions, and extracts from culture filtrate, spore germination fluid or mycelial mats, extracts were diluted 10 to 1,000 times in distilled water and placed onto the lower surface of detached leaves of Citrus iyo cv. Iyokan as described previously (18-20). Leaves were incubated in a moist chamber at $24^{\circ} \mathrm{C}$ in the dark, and necrosis development on the leaves was monitored for $48 \mathrm{~h}$. For pathogenicity assays, spores of each isolate were collected from mycelial mats grown in PDB for 3 weeks and suspended in water at $1 \times 10^{5}$ spores $/ \mathrm{ml}$ and spray-inoculated on the lower surface of detached young leaves (midrib length 3.0 to $4.0 \mathrm{~cm}$ ) of ACTtoxin-sensitive citrus cultivar Iyokan as described previously (1820). Leaves were incubated in a moist chamber for 24 to $48 \mathrm{~h}$ at $24^{\circ} \mathrm{C}$ in the dark, and the development of leaf spots and necrosis was monitored.

Pulse-field gel electrophoresis (PFGE) and hybridization. Preparation of chromosomes from fungal protoplasts and PFGE was carried out according to methods described previously (6, $18,20)$. Running conditions (duration, voltage, linear gradient of switching time) in a PFGE apparatus (CHEF-DRII, Bio-Rad, Richmond, CA) consisted of $0.5 \times \mathrm{TBE}(28)$ at $8^{\circ} \mathrm{C}$ in a $0.8 \%$ agarose gel (Seakem Gold agarose, BioWhittaker Molecular Applications, Rockland, ME), 13 h/5.4 V/cm/120 s, 13 h/5.4 V/ $\mathrm{cm} / 180 \mathrm{~s}$. Chromosomal DNA bands were visualized by ethidium bromide staining, and the gel was serially treated by soaking in $0.2 \mathrm{~N} \mathrm{HCl}$ for $20 \mathrm{~min}$ (to nick chromosomal DNA), and then $0.4 \mathrm{~N} \mathrm{NaOH}$ plus $1.5 \mathrm{M} \mathrm{NaCl}$ for $30 \mathrm{~min}$ and transferred to Hybond- $\mathrm{N}^{+}$membrane (Amersham Biosciences, Piscataway, $\mathrm{NJ}$ ) by alkaline capillary transfer (28) with $0.4 \mathrm{~N} \mathrm{NaOH}$ and $1.5 \mathrm{M}$ $\mathrm{NaCl}$ for $48 \mathrm{~h}$. The membrane was baked at $120^{\circ} \mathrm{C}$ for $30 \mathrm{~min}$ to fix the DNA and hybridized at $68^{\circ} \mathrm{C}$ overnight with ACTT5 or ACTT6 probes labeled with the DIG-PCR labeling kit (Roche, Basel, Switzerland). Primer sets used for the preparation of ACTT5 and ACTT6 probes were as described for the RT-PCR analysis above. Hybridization and washes were conducted under highly stringent conditions according to the manufacturer's instructions as described previously $(18,20)$.

\section{RESULTS}

Identification and genomic analysis of ACT-toxin biosynthesis genes ACTT5 and ACTT6 from cosmid clone pcCL4-1. Five genes including ACTT5 (accession AB444613) encoding a putative acyl-CoA synthetase, and ACTT6 (accession AB444614) 
encoding a putative enoyl-CoA hydratase, were identified from the cosmid clone pcCL4-1 (accession AB176941) of the tangerine pathotype (Fig. 2A). ACTT5 (accession AB444613) was 1,883 bp in length with a predicted 578 amino acid protein and three introns of $46 \mathrm{bp}$ (base pairs 123 to 168), $47 \mathrm{bp}(1,216$ to 1,262$)$, and $53 \mathrm{bp}(1,468$ to 1,520$)$ confirmed by comparison with the cDNA sequence. ACTT6 (accession AB444614) was $897 \mathrm{bp}$ and encoded a deduced 298 amino acid protein with no introns. BLAST searches indicated that ACTT5 likely encodes an acyl-CoA synthetase and ACTT6 likely encodes an enoyl-CoA hydratase. PFGE and Southern blotting demonstrated that ACTT5 and ACTT6 are located on the same small chromosome (1.9 to $2.0 \mathrm{Mb})$ among several isolates of the tangerine pathotype of $A$. alternata obtained from citrus groves in Florida (Fig. 2B).

The distribution of ACTT5 and ACTT6 in the genome of strain $\mathrm{SH} 20$ of the tangerine pathotype was further examined by genomic Southern blotting (Fig. 3). The ACTT5 probe detected two to four fragments when genomic DNA was digested with the restriction enzymes BamHI, EcoRI, PstI, SalI, and XhoI, which have no predicted restriction sites within the gene sequence (Fig. $3 \mathrm{~A})$. Expected bands were observed, such as the $18.8-\mathrm{kb}$ fragment in the BamHI-digested DNA as well as 9.3-kb fragment in the XhoI digest (Fig. 3A andB). However, additional unexpected bands were observed based on the restriction map of pcCL4-1, such as the 9.0-kb band in the BamHI digest and 7.5-, 13.5-, and 19.0-kb bands in the XhoI digest (Fig. 3A and B), indicating that there are multiple copies of ACTT5 in the genome. The ACTT6 probe detected one to three fragments when genomic DNA was digested with BamHI, EcoRI, EcoRV, PstI, SalI, and XhoI, which have no predicted restriction sites within the gene sequence (Fig. $3 \mathrm{~A})$. Expected bands, such as the $18.8-\mathrm{kb}$ fragment after digestion with $\mathrm{BamHI}$ as well as 9.3-kb fragment in the XhoI digest (Fig. $3 \mathrm{~A}$ and $\mathrm{B}$ ), were observed using the ACTT6 probe. However, similar to the results for ACTT5, detection of unexpected bands based on the restriction map of pcCL4-1, such as a 9.5-kb band after BamHI digestion and 7.5- and 18.0-kb bands in the XhoI digest (Fig. 3A and B), indicated the presence of additional ACTT6 copies.
The distribution of ACTT5 and ACTT6 among various A. alternata pathotypes (tangerine, rough lemon, Japanese pear, strawberry, tomato, apple, and tobacco), nonpathogenic strains of $A$. alternata, and a dual pathotype isolate producing both ACT- and ACR-toxins (18) was determined using genomic Southern blot analysis (Fig. 4). ACTT5 and ACTT6 homologues were detected in the genomes of Japanese pear and strawberry pathotype isolates and the dual pathotype isolate, but not in any other pathotype (Fig. 4). The distribution of ACTT5 and ACTT6 among 14 tangerine pathotype isolates sampled from different geographical regions was also determined using genomic Southern hybridization (Fig. 4). ACTT5 and ACTT6 probes hybridized to only those worldwide isolates that produced ACT-toxin and were pathogenic to citrus hosts susceptible to the tangerine pathotype. These probes did not hybridize to any nonpathogenic isolates in this worldwide sample, indicating that presence of ACTT5 and ACTT6 was highly correlated to ACT-toxin production and pathogenicity (Fig. 4).

Function of ACTT5 in ACT-toxin biosynthesis. To examine the role of ACTT5 in pathogenicity and ACT-toxin biosynthesis, the gene replacement vector pPCR-Script::ACTT5::hph was constructed. The vector contained partial ACTT5 sequences with an $h p h$ cassette for replacement disruption of ACTT5 mediated by homologous recombination (Fig. 5A). Reference tangerine pathotype isolate SH20 (18-20) was transformed with pPCR-Script:: ACTT5::hph, and 10 transformants were selected. Screening the toxicity of culture filtrates and genomic Southern hybridization analysis of the transformants identified transformant 1-8, which showed a reduction in toxicity as well as a shift in the $3.0-\mathrm{kb}$ ACTT5 band present in the wild type to a $5.5-\mathrm{kb}$ band in the transformant. This indicated insertion of the vector construct at the target site (Fig. 5A and C). Another native band of $2.1 \mathrm{~kb}$ remained intact (Fig. 5C). The $h p h$ probe hybridized only to the $5.5-\mathrm{kb}$ band of transformant 1-8 (data not shown) suggesting that ACTT5 exists in more than one copy in the genome of SH20 and the vector construct was inserted in only one of the copies. Transcript analysis of ACTT5 by RT-PCR with primer set ACTT5S1F1 and ACTT5S1R1 generated an amplicon of predicted size

A
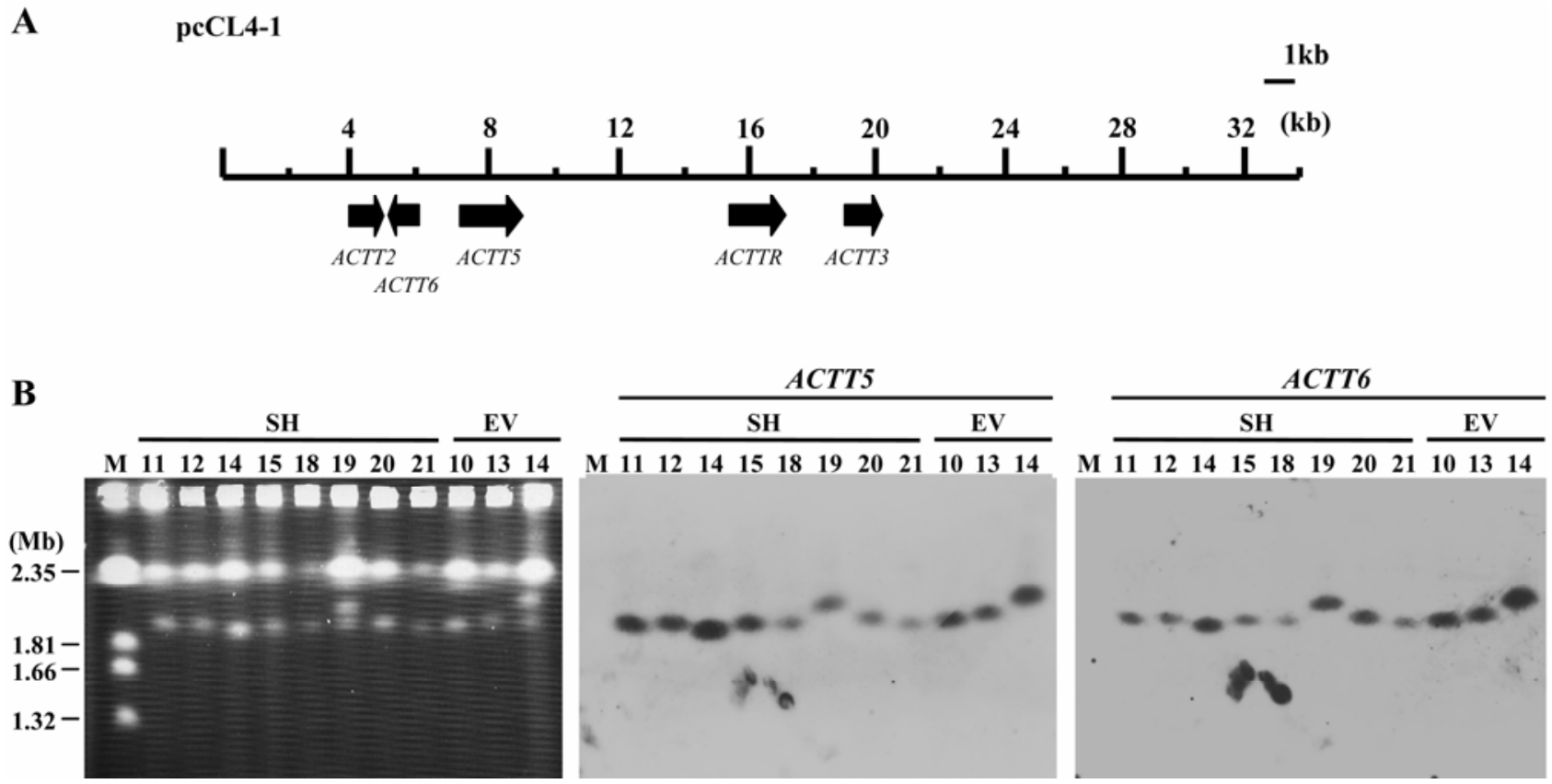

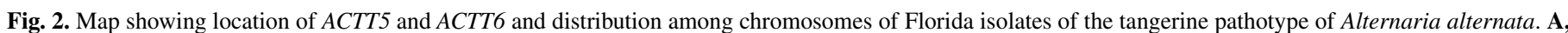

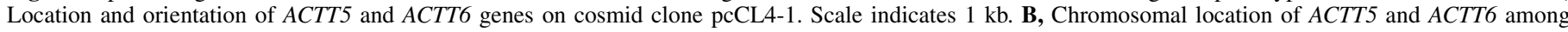

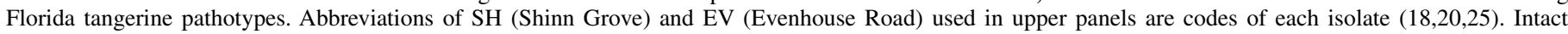

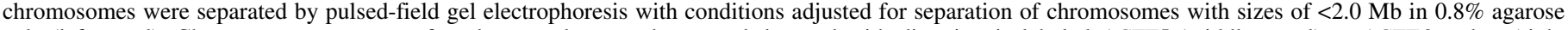

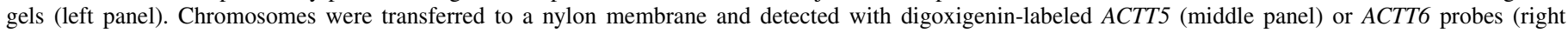
panel). Hansenula wingei chromosome size markers are indicated at left. 
(959 bp) from total RNA of wild type and transformant 1-8, and the product hybridized to the ACTT5 probe (Fig. 6A). Intensity of the band was reduced in the transformant 1-8 compared with that of wild type (Fig. 6A). The PCR reaction without addition of reverse transcriptase did not amplify a product, and an actin gene, which is known to be expressed constitutively, was amplified equally in the disruptant and wild type (Fig. 6A). A reduction of approximately $70 \%$ in ACT-toxin peak area was observed in transformant 1-8 (Fig. 6C). When spores of transformant 1-8 were spray-inoculated onto the lower leaf surfaces of susceptible cv. Iyokan, typical leaf spots were apparent but disease severity was reduced relative to inoculation with the wild type (Fig. 6D).

To disrupt the remaining copy of ACTT5, an ACTT5 PCR fragment was amplified using primer set ACTT5S1F1 and ACTT5R2EcoRI and subcloned into the EcoRV site of transfor-
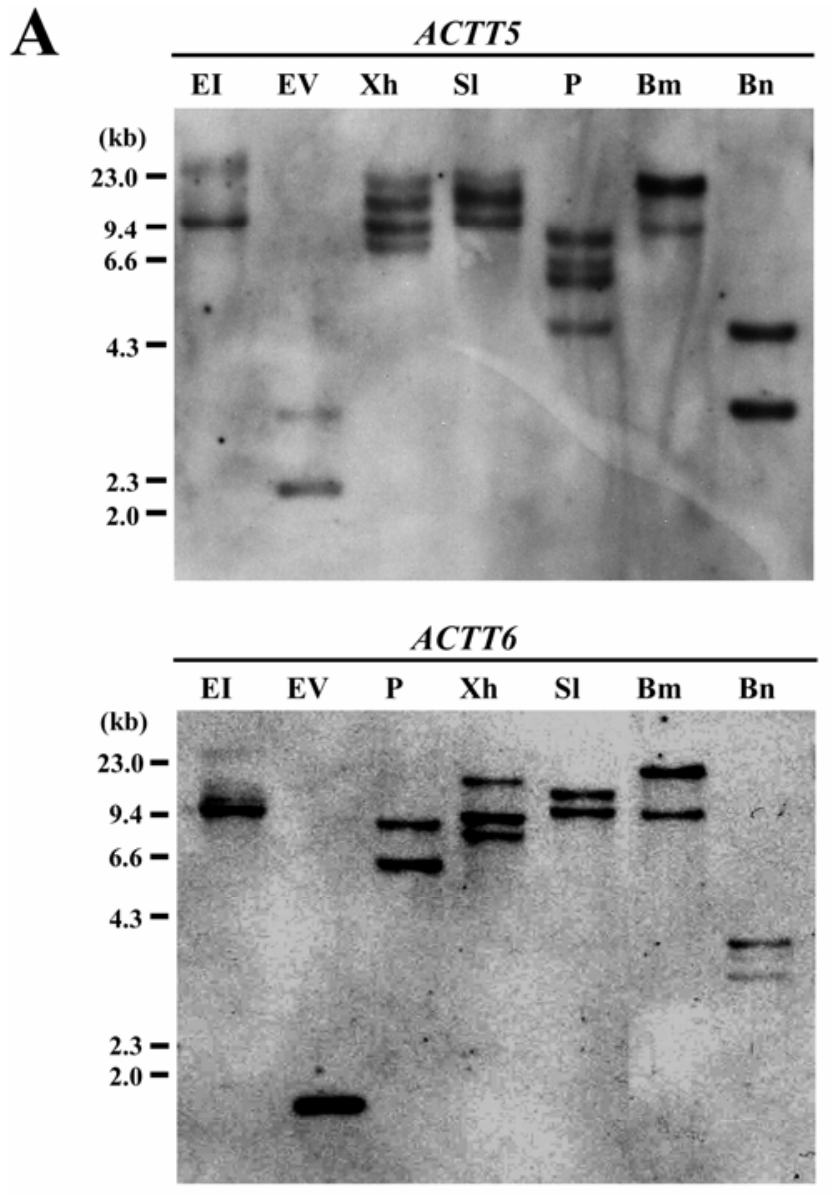

B

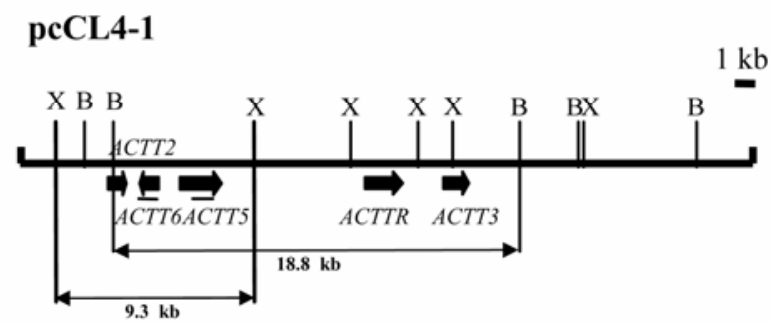

Fig. 3. Genomic Southern blot analysis of ACTT5 and ACTT6 in the tangerine pathotype of Alternaria alternata using several restriction enzymes. A, DNA of isolate SH20 digested with EcoRI (lane EI), EcoRV (EV), XhoI (Xh), SalI (S1), PstI (P), BamHI (Bm), and BanIII (Bn), respectively. Digested DNA was transferred to a nylon membrane and probed with digoxigenin-labeled ACTT5 or ACTT6 probe. Sizes of marker DNA fragments (HindIII-digested $\lambda$ DNA) are indicated at left. B, Restriction map of the cosmid clone pcCL4-1. B and X in the map indicate the restriction sites for BamHI and XhoI, respectively. Scale indicates $1 \mathrm{~kb}$.

mation vector pII99 carrying the NPTII cassette to generate pII99::ACTT5. The single copy disruptant 1-8 was retransformed with pII99::ACTT5, and 24 transformants were selected. Bioassay of toxicity in the culture filtrates and genomic Southern hybridization analysis of the transformants identified transformant 8-32, which showed a reduction in toxicity as well as a shift of a 2.1-kb ACTT5 band in the wild type to a $7.9-\mathrm{kb}$ band in the transformant. This indicated that the vector construct inserted in another copy of the target gene (Fig. 5B and C). Although two distinct copies of ACTT5 were disrupted with the respective vectors, the native $2.1-\mathrm{kb}$ band remained (Fig. 5C), suggesting that ACTT5 exists as more than two copies in the genome of isolate SH20 (Fig. 3). Transcript analysis of ACTT5 by RT-PCR generated an amplicon of predicted size ( $959 \mathrm{bp}$ ) from total RNA of the transformant $8-32$, and the product hybridized to the ACTT5 probe (Fig. 6A). The intensity of the band was reduced in transformant 8-32 compared with that of the single copy disruptant 1-8 or wild type (Fig. 6A). Production of ACT-toxin in culture filtrates was greatly reduced $(97.4 \%$ reduction in peak area) in transformant 8-32 (Fig. 6C), and inoculation of transformant 8-32 on detached leaves showed a great reduction in disease (Fig. 6D) compared to those of the single copy disruptant 1-8 or wild type. No differences in growth (Fig. 6B), sporulation, and spore germination rate were detected among wild type, single copy disruptant 1-8, or double copy disruptant 8-32.

Targeted gene disruption of ACTT6 for functional analysis in ACT-toxin biosynthesis. To examine the role of ACTT6 in

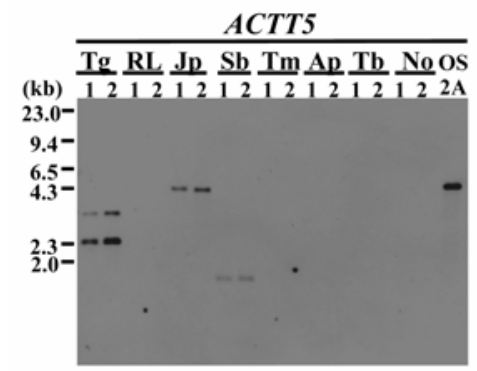

ACTT5

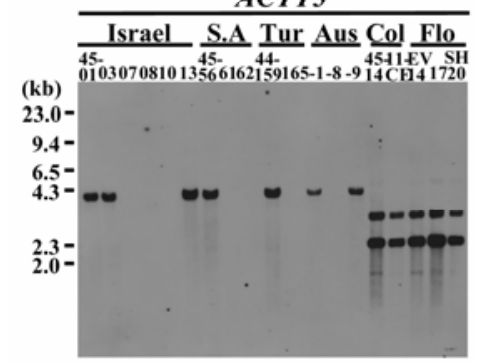

Toxin ++---++--+-+-++++++

Patho $\frac{++-\cdots++--+-+-++++++}{++-\cdots++--+-+-++++++}$ among worldwide isolates of Alternaria alternata. Genomic DNA of seven distinct pathotypes and one dual pathotype isolate (upper panels), and worldwide tangerine pathotype strains including several nonpathogenic strains (lower panels) digested with EcoRV was hybridized with digoxigenin-labeled ACTT5 or ACTT6 probes. Abbreviations used in upper panels are as follow: $\mathrm{Tg}$ (tangerine pathotype isolates SH11 [lane 1] and SH20 [lane 2]), RL (rough lemon pathotype isolates HC1 [lane 1] and HC8 [lane 2]), JP (Japanese pear pathotype isolates G31 [lane 1] and G90-A2 [lane 2]), Sb (strawberry pathotype isolates NAF-3 [lane 1] and NAF-8 [lane 2], Tm (tomato pathotype isolates 91080804 [lane 1] and AL-4 [lane 2]), Ap (apple pathotype isolates AM-1 [lane 1] and O-159 [lane 2]), Tb (tobacco pathotype isolates No. 122-2 [lane 1] and AT204 [lane 2]), No (nonpathogenic isolates O-94 [lane 1] and HC14 [lane 2]), and OS2A (dual pathotype isolate BC3-5-1-OS2A [18]), respectively. Abbreviations used in lower panels are as follow: Israel (Israel), South Africa (SA), Turkey (Tur), Australia (Aus), Colombia (Col), and Florida (Flo), respectively. Production of ACT-toxin (Toxin) and pathogenicity phenotype on tangerine (Patho) is indicated with + or - below each lane. Sizes of marker DNA fragments (HindIII-digested $\lambda$ DNA) are indicated at left. 
pathogenicity and ACT-toxin production, the disruption vector pSH75::ACTT6 was constructed. The vector contained two partial ACTT6 sequences with an $h p h$ cassette (Fig. 5D) for ACTT6 disruption mediated by homologous recombination. A screen for reduced ACT-toxin production and Southern hybridization identified transformant 53, which showed a reduction in the toxicity in culture filtrates and loss of a 9.5-kb ACTT6 band. This indicated insertion of the vector at the target site due to replacement of the genomic region with the $h p h$ cassette carried on pSH75::ACTT6. The $h p h$ probe identified an expected $11.3-\mathrm{kb}$ band, which has an insertion of pSH75::ACTT6 into the 9.5-kb band of the wild type (Fig. 5D and F). Transcript analysis of ACTT6 by RT-PCR with primer set ACTT6F1 and ACTT6R1 generated an amplicon of predicted size $(812 \mathrm{bp})$ from total RNA of the wild type and transformant 53 , and the product hybridized to the ACTT6 probe (Fig. 6E). Intensity of the band was greatly reduced in transformant 53 compared with that of wild type (Fig. 6E). The PCR reaction without addition of reverse transcriptase did not amplify a product, and the actin gene was amplified equally in both disruptant and wild type (Fig. 6E). Production of ACT-toxin by transformant 53 was reduced approximately $70 \%$ compared with wild type (Fig. 6G). When spores of transformant 53 were spray-
A

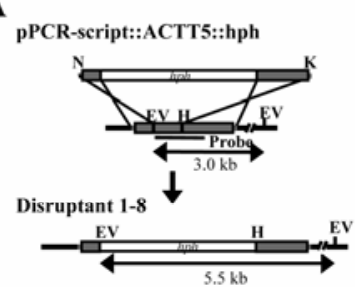

B

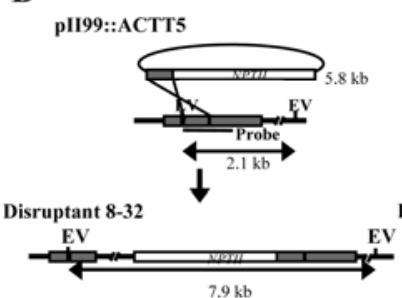

C

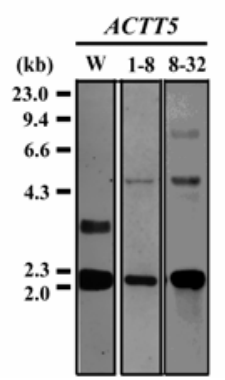

D

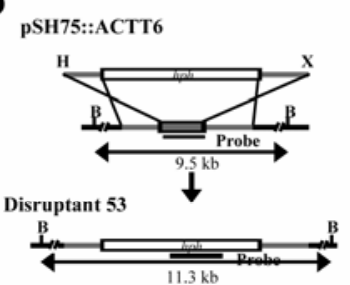

$\mathbf{E}$ pII99::ACTT6
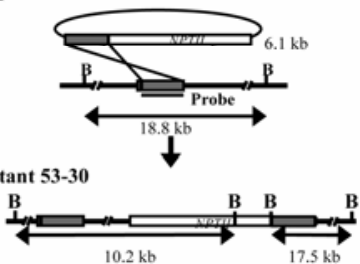

F

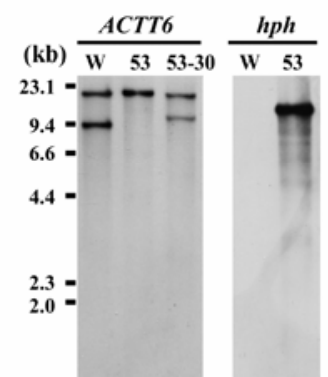
Disruptant 53-30

Fig. 5. Targeted gene disruption of ACTT5 and ACTT6 in the tangerine pathotype of Alternaria alternata. A, Disruption construct pPCR-script:: ACTT5::hph and integration pattern in single copy disruptant 1-8. N, K, EV, and $\mathrm{H}$ are abbreviations used for NotI, KpnI, EcoRV, and HindIII restriction sites, respectively. B, Disruption construct pII99::ACTT5 and integration pattern in double copy disruptant 8-32. C, Genomic Southern blot of ACTT5 in wild type (W), single copy disruptant 1-8, and double copy disruptant 8-32. Genomic DNA was digested with EcoRV and fractionated in a $0.8 \%$ agarose gel followed by hybridization with ACTT5 probe. D, Disruption construct pSH75::ACTT6 and integration pattern in single copy disruptant 53. B and X are abbreviations used for BamHI and XhoI restriction sites, respectively. E, Disruption construct pII99::ACTT6 and integration pattern in double copy disruptant 53-30. F, Genomic Southern blot of ACTT6 in wild type (W), single copy disruptant 53, and double copy disruptant 53-30. Genomic DNA was digested with $\mathrm{BamHI}$ and fractionated in a $0.8 \%$ agarose gel followed by hybridization with an ACTT6 probe or $h p h$ probe. Sizes of marker DNA fragments (HindIII-digested $\lambda$ DNA) are indicated at left. inoculated onto the lower surface of Iyokan leaves, typical leaf spots appeared but disease severity was reduced relative to wild type (Fig. 6H).

To disrupt the second copy of ACTT6, an ACTT6 PCR fragment was amplified using the primer set ACTT6F1 and ACTT6R1 and subcloned into the EcoRV site of transformation vector pII99 carrying the NPTII cassette to generate pII99::ACTT6 (Fig. 5E). The single copy disruptant 53 was retransformed with pII99:: ACTT6, and 36 transformants were tested for ACT-toxin production. Culture filtrates from seven transformants $(53-6,-9,-30,-31$, $-35,-39$, and -42 ) were not toxic to Iyokan. Integration of pII99:: ACTT6 at the target site in one (53-30) of the transformants was
$\mathbf{A}$
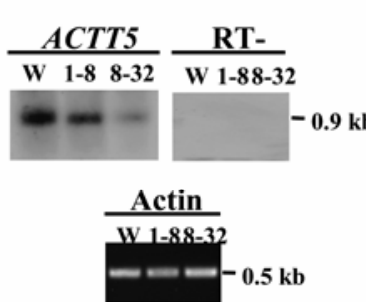

B

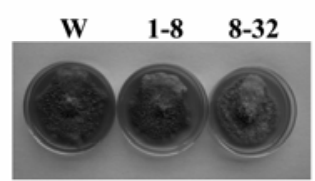

C

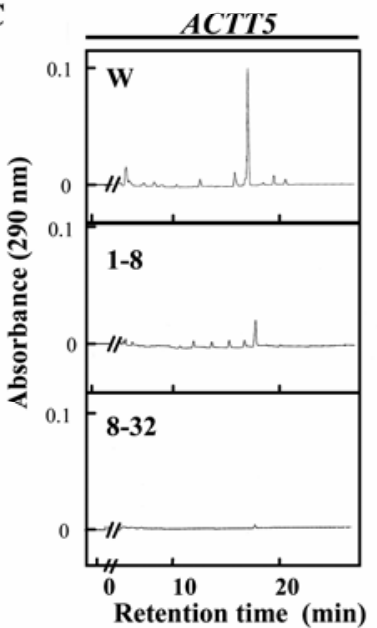

D

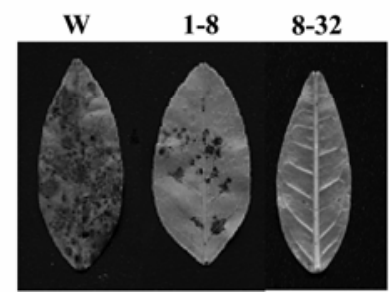

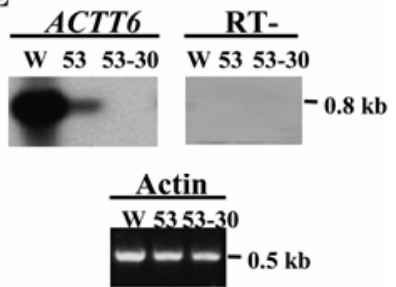

$\mathbf{F}$

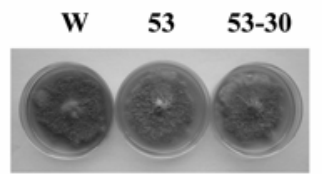

G

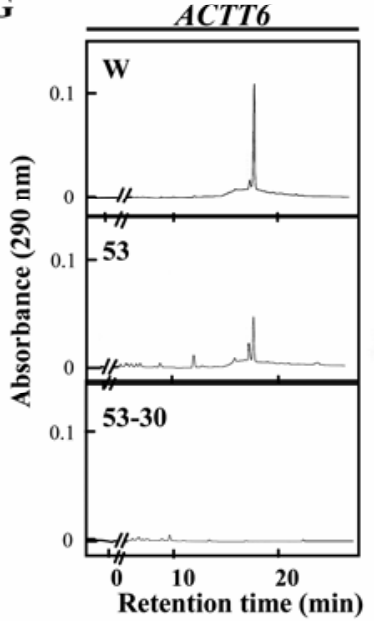

$\mathbf{H}$

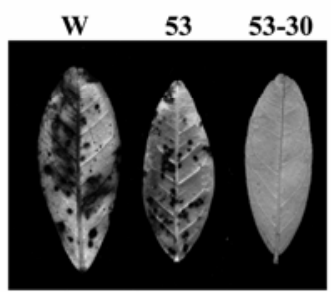

Fig. 6. Reverse transcription-polymerase chain reaction (RT-PCR) detection, ACT-toxin production, and pathogenicity of ACTT5- or ACTT6-disruptants. A and E, RT-PCR detection of ACTT5 (A) or ACTT6 (E) transcripts in wild-type SH20 (lane W), single copy ACTT5 disruptant 1-8, single copy ACTT6 disruptant 53, double copy ACTT5 disruptant 8-32, or double copy ACTT6 disruptant 53-30, respectively. RT- indicates controls without addition of reverse transcriptase. Amplification of an actin gene was used as a positive control of the RT-PCR system as well as for equal addition of RNA. B and F, Growth of wild-type isolate $\mathrm{SH} 20$ (W) and disruptants on potato dextrose agar plates. C and G, High-performance liquid chromatography traces of extracts from culture filtrates of ACTT5 disruptants (C) and ACTT6 disruptants (G). D and $\mathbf{H}$, Pathogenicity tests of disruptants using spray-inoculation with conidia of ACTT5 disruptants (D) and ACTT6 disruptants $(\mathbf{H})$ on Iyokan leaves. 
analyzed by Southern blotting, and transformant 53-30 showed the expected bands of 10.2 and $17.5 \mathrm{~kb}$ instead of the single 18.8$\mathrm{kb}$ band in transformant 53 and the wild type (Fig. 5E and F). No ACTT6 transcript was detected in transformant 53-30 by RT-PCR (Fig. 6E). HPLC analysis also did not detect any trace of ACTtoxin in the culture filtrates of transformant 53-30 (Fig. 6G), and inoculation of plants with transformant 53-30 did not induce any necrotic spots on Iyokan leaves (Fig. 6H). No differences in growth rate (Fig. $6 \mathrm{~F}$ ), sporulation and spore germination rate were detected among the wild type, single copy disruptant 53, and double-copy disruptant 53-30.

A putative precursor of ACT-toxin in ACTT6 disruptants. Accumulation of a putative precursor of ACT-toxin was detected using HPLC of culture filtrates and mycelium of ACTT6 disruptant 53-30. Disruptant 53-30 produced no detectable ACTtoxin nor any other major product in culture filtrates extracted with ethyl acetate (Figs. 6G and 7A), while a new peak appeared on an HPLC trace from methanol extracts of mycelium (Fig. 7A). The peak was not observed in the extracts of wild type mycelium, but appeared in the mycelium of single copy disruptant 53 and accumulated to a greater extent in the double copy disruptant 5330 (Fig. 7A). The peak was collected following large-scale preparation, and run on a TLC plate after confirmation of retention time (28 $\mathrm{min}$ ) as a single peak by HPLC under the same conditions (Fig. 7B). A single spot was observed with an $\mathrm{Rf}$ value of 0.28 under $315 \mathrm{~nm}$ UV irradiation and no other spot was observed even following $\mathrm{H}_{2} \mathrm{SO}_{4}$ spray detection (Fig. 7C). Although no peak was detected in the wild type by HPLC (Fig. 7A), a trace of a spot at $\mathrm{Rf} 0.28$ was detected in the wild type when the corresponding HPLC fractions were collected and concentrated for TLC detection (Fig. 7C). Neither the extract from mycelial mats, the collected HPLC peak (Fig. 7B), nor the TLC spot at Rf 0.28 (Fig. 7C) from 53-30 showed toxicity to Iyokan leaves.

\section{DISCUSSION}

Five genes were identified on a $34-\mathrm{kb}$ genomic sequence of the $1.9 \mathrm{Mb}$ chromosome from the tangerine pathotype of A. alternata. We characterized two of these and present biochemical and molecular genetic evidence for the involvement of a putative acylCoA synthetase (ACTT5) and a putative enoyl-CoA hydratase (ACTT6) in ACT-toxin production and pathogenicity. The tangerine pathotype isolate SH20 makes ACT-toxin and has a $1.9 \mathrm{Mb}$ chromosome that carries the biosynthetic genes controlling toxin production (18-20). Genes required for the synthesis of Alternaria HSTs are tightly clustered, such as the AK-toxin TOX cluster $(A K T)$ controlling AK-toxin production (31), and the AFtoxin TOX cluster (AFT) controlling AF-toxin production (6). Genes responsible for ACT-toxin production (ACTT1, 2, 3, R, 5, and 6 ) are also clustered, and the cluster has been designated as ACT-toxin TOX cluster (ACTT) (A. Masunaka, Y. Miyamoto, K. Gomi, and K. Akimitsu, unpublished data). These genes are located on a single 1.9 to $2.0 \mathrm{Mb}$ chromosome in ACT-toxin producing isolates from Florida (18). Generally only A. alternata strains producing HSTs are known to possess chromosomes of less than $2.0 \mathrm{Mb}(1,19,20)$ and nonpathogenic strains do not have any small chromosomes. Since these small chromosomes do not carry genes essential for normal growth and reproduction and loss of these chromosomes has no obvious phenotypic effect, these chromosomes have been called conditionally dispensable chromosomes $(6,33)$. Interestingly, gene clusters responsible for the biosynthesis of HST, such as the AKT, AFT, and ACTT clusters in the Japanese pear, strawberry, and tangerine pathotypes $(4,18-$ 20), are all located in small dispensable chromosomes. Genomic regions in these $A K T, A F T$, and $A C T T$ clusters are similar and several genes responsible for production of the common 9,10epoxy-8-hydroxy-9-methyl-decatrienoic (decatrienoic) acid moiety of AK-, AF-, and ACT-toxins $(6,9,18-20,27,31,32)$ were identi-
A
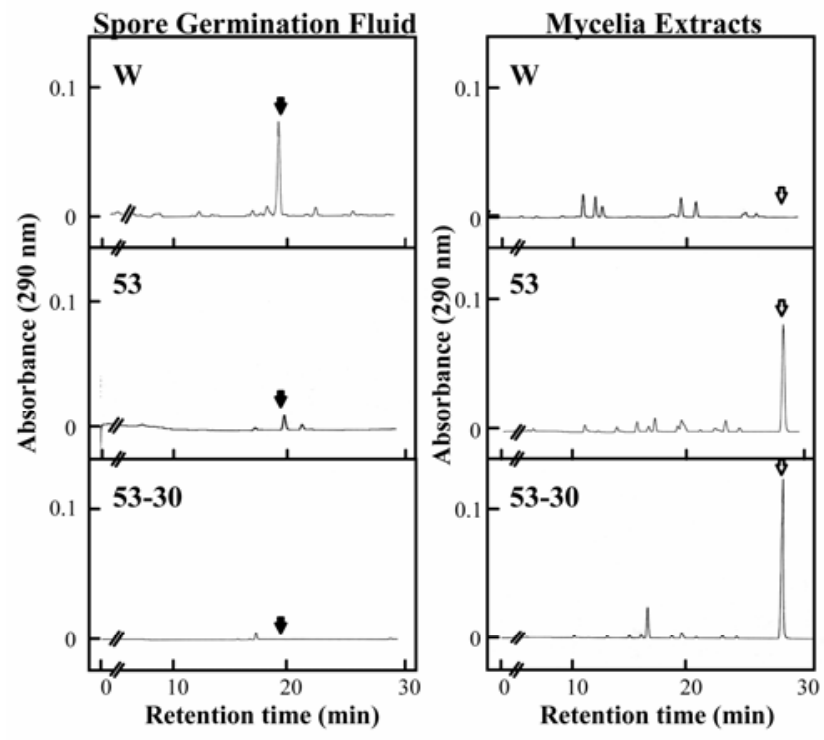

$\mathbf{B}$
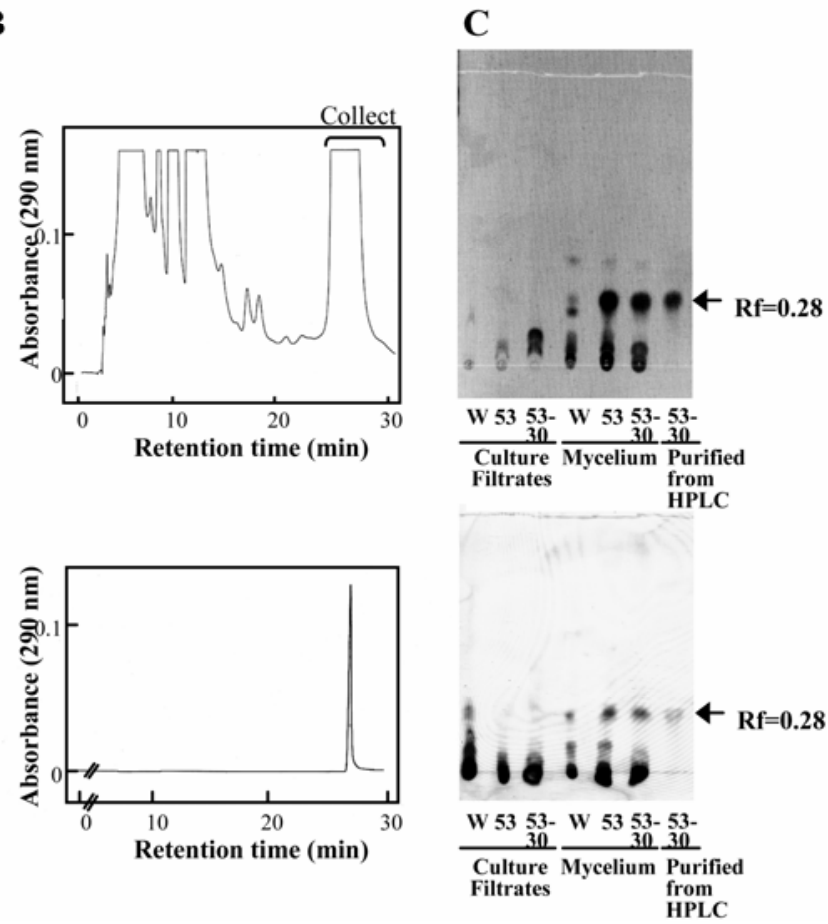

Fig. 7. High-performance liquid chromatography (HPLC) and thin-layer chromatographic (TLC) identification of a putative decatrienoic intermediate in ACT-toxin biosynthesis produced by double copy ACTT6 disruptant 53-30. A, HPLC traces of extracts from spore germination fluid (left panel) and mycelial mats (right panel) of wild-type SH20 (W), ACTT6 single copy disruptant 53, and double copy disruptant 53-30. Solid arrows indicate the ACT-toxin peak and open arrows indicate the peak of the putative intermediate compound. HPLC was carried out using a Develosil ODS-5 analytic column $(4.6 \times 250 \mathrm{~mm})$ and $290 \mathrm{~nm}$ detection (15). B, HPLC traces of partial purification of mycelial extracts from ACTT6 disruptant 53-30. HPLC was carried out for a large preparation (upper chart) using a Megapak SIL $\mathrm{C}_{18} \mathrm{~T}$ preparative column $(10 \times 250 \mathrm{~mm})$ with an acetonitrile/deionized water $(50: 50, \mathrm{vol} / \mathrm{vol})$ solvent system, a flow rate of $3 \mathrm{ml}$ per minute and $290 \mathrm{~nm}$ detection. The peak collected from retention time 25 to $30 \mathrm{~min}$ was run on a Develosil ODS-5 analytic column (lower panel) with same conditions as described for panel A for confirmation of the collected peak. $\mathbf{C}$, The purified compounds were separated by TLC using a solvent system of benzene/acetic acid (90:10, vol/vol), and detected as a purple spot under $315 \mathrm{~nm}$ UV (upper panel) or detected by spraying with sulfuric acid/ethanol. Samples were prepared from culture filtrates or mycelia, and further purified using HPLC, from either wild-type isolate SH20 (W), single copy disruptant 53, or double copy disruptant 53-30 of ACTT6. 
fied as homologues of each other. Distribution of ACTT5 and ACTT6 in seven pathotypes, a nonpathogenic strain, and worldwide strains of A. alternata corresponds well with these previous findings. ACTT5 and ACTT6 were found on the genomes of tangerine, Japanese pear, and strawberry pathotypes among seven pathotypes of A. alternata, and presence of these genes is correlated with ACT-toxin production and pathogenicity among $A$. alternata isolated from citrus fields around the world.

The nucleotide sequence of ACTT5 is $1,883 \mathrm{bp}$ in length with three introns and encodes a putative 578 amino acid protein which shows a sequence similarity to acyl-CoA synthetase. Our reference strain SH20 of the tangerine pathotype (18-20) has multiple copies of ACTT5 as determined by genomic Southern blot analysis. We generated single and two copy disruptants of ACTT5 using gene replacement mediated by homologous recombination. The two copy disruptant 8-32 showed markedly reduced ACTtoxin production and pathogenicity. A complete disruptant of ACTT5 function has not been generated due to the remaining copies of ACTT5. Genes involved in HST production in Alternaria are often present as multiple copies $(4-6,9,10,18-20,27$, 31,32 ), and this multiplication makes it difficult to disrupt all functional copies of the target genes due to lack of selectable markers for multiple transformations with different vector constructs as well as low the efficiency of homologous recombination in Alternaria spp. Since RNA silencing was successfully introduced for dysfunction of all copies of ACTT2, which has multiple copies in the genome of isolate SH20 (20), this method may be applicable for further functional analysis of ACTT5. However, we think the data presented here confirm that ACTT5 is involved in ACT-toxin production, because each gene disruption correlated with a reduction in ACT-toxin production as well as reduced pathogenicity, as has been shown for other HST biosynthesis genes $(4-6,9,10,18-20,27,31,32)$.

ACTT6 is comprised of 897 bp with no introns, and encodes a putative 298 amino acid protein. A BLAST search revealed that ACTT6 shows sequence similarity to enoyl-CoA hydratase. The complete loss of ACTT6 transcript accumulation by disruption of two functional copies of ACTT6 led to a complete loss of ACTtoxin production and pathogenicity. Furthermore, we detected a putative intermediate compound due to the disruption of the step catalyzed by ACTT6 in the ACT-toxin biosynthesis pathway, and accumulation of this compound was inversely proportional to reduction of ACT-toxin production by ACTT6 disruption. Since ACTT6 homologues are present in the genomes of the Japanese pear, strawberry and tangerine pathotypes, ACTT6 is likely a part of the biosynthesis pathway of the 9,10-epoxy-8-hydroxy-9methyl-decatrienoic acid moiety shared by AK-, AF-, and ACTtoxins $(4-6,9,18-20,27,31,32)$. Thus, the accumulated putative compound may be an intermediate structure of decatrienoic acid with fatty acid properties, including high hydrophobicity. This property may be the reason why this compound is not secreted into the culture filtrate and accumulated in mycelial mats. Although the purified compound appears to be a single peak by HPLC and also a single spot by TLC, nuclear magnetic resonance analysis revealed some contamination in the fraction (data not shown) and further purification will be necessary to identify the chemical structure of the compound.

\section{ACKNOWLEDGMENTS}

We thank L. W. Timmer, for continuous support of this project and for providing all Florida strains of A. alternata; and M. Kodama and $\mathrm{H}$. Otani, Tottori University, for valuable discussions and providing strain O94. This work was supported by grants for scientific research on priority area (A) from Ministry of Education, Culture, Sports, Science, and Technology of Japan; Precursory Research for Embryonic Science and Technology from Japan Science and Technology Agency; and Special Coordination Funds for Promoting Sciences from Ministry of Education, Culture, Sports, Science, and Technology of Japan.

\section{LITERATURE CITED}

1. Akamatsu, H., Taga, M., Todama, M., Johnson, R., Otani, H., and Kohmoto, K. 1999. Molecular karyotypes for Alternaria plant pathogens known to produce host-specific toxins. Curr. Genet. 35:647-656.

2. Akimitsu, K., Peever, T. L., and Timmer, L. W. 2003. Molecular, ecological and evolutionary approaches to understanding Alternaria diseases of citrus. Mol. Plant Pathol. 4:435-446.

3. Cullen, D., Leong, S. A., Wilson, L. J., and Henner, D. J. 1987. Transformation of Aspergillus nidulans with the hygromycin-resistance gene, hph. Gene 57:21-26.

4. Harimoto, T., Hatta, R., Kodama, M., Yamamoto, M., Otani, H., and Tsuge, T. 2007. Expression profiles of genes encoded by the supernumerary chromosome controlling AM-toxin biosynthesis and pathogenicity in the apple pathotype of Alternaria alternata. Mol. Plant-Microbe Interact. 12:1463-1476.

5. Harimoto, T., Tanaka, T., Kodama, M., Yamamoto, M., Otani, H., and Tsuge, T. 2008. Multiple copies of $A M T 2$ are prerequisite for the apple pathotype of Alternaria alternata to produce enough AM-toxin for expressing pathogenicity. J. Gen. Plant Pathol. 74:222-229.

6. Hatta, R., Ito, K., Hosaki, Y., Tanaka, T., Tanaka, A., Yamamoto, M., Akimitsu, K., and Tsuge, K. 2002. A conditionally dispensable chromosome controls host-specific pathogenicity in the fungal plant pathogen Alternaria alternata. Genetics 161:59-70.

7. Isshiki, A., Akimitsu, K., Yamamoto, M., and Yamamoto H. 2001. Endopolygalacturonase is essential for citrus black rot caused by Alternaria citri but not brown spot caused by Alternaria alternata. Mol. Plant-Microbe Interact. 14:749-757.

8. Isshiki, A., Ohtani, K., Kyo, M., Yamamoto, H., and Akimitsu, K. 2003. Green fluorescent detection of fungal colonization and endopolygalacturonase gene expression in the interaction of Alternaria citri with citrus. Phytopathology 93:768-773.

9. Ito, K., Tanaka, Hatta, R., Yamamoto, M., Akimitsu, K., and Tsuge, T. 2004. Dissection of the host range of the fungal plant pathogen Alternaria alternata by modification of secondary metabolism. Mol. Microbiol. $52: 399-411$

10. Johnson, R. D., Johnson, L., Itoh, Y., Kodama, M., Otani, H., and Kohmoto, K. 2000. Cloning and characterization of a cyclic peptide synthetase gene from Alternaria alternata apple pathotype whose product is involved in AM-toxin synthesis and pathogenicity. Mol. Plant-Microbe Interact. 13:742-753.

11. Katoh, H., Isshiki, A., Masunaka, A., Yamamoto, H., and Akimitsu, K. 2006. A virulence-reducing mutation in the postharvest citrus pathogen Alternaria citri. Phytopathology 96:934-940.

12. Katoh, H., Nalumpang, S., Yamamoto, H., and Akimitsu, K. 2007. Overexpression of citrus polygalacturonase-inhibiting protein in citrus black rot pathogen Alternaria citri. J. Plant Physiol. 164:527-535.

13. Kimura, N., and Tsuge, T. 1993. Gene cluster involved in melanin biosynthesis of the filamentous fungus Alternaria alternata. J. Bacteriol. 175:4427-4435.

14. Kohmoto, K., Akimitsu, K., and Otani, H. 1991. Correlation of resistance and susceptibility of citrus to Alternaria alternata with sensitivity to hostspecific toxins. Phytopathology 81:719-722.

15. Kohmoto, K., Itoh, Y., Shimomura, N., Kondoh, Y., Otani, H., Kodama, M., Nishimura, S., and Nakatsuka, S. 1993. Isolation and biological activities of two host-specific toxins from the tangerine pathotype of Alternaria alternata. Phytopathology 83:495-502.

16. Kohmoto, K., and Otani, H. 1991. Host recognition by toxigenic plant pathogens. Experientia 47:755-764.

17. Kohmoto, K., Scheffer, R. P., and Whiteside, J. O. 1979. Host-selective toxins from Alternaria citri. Phytopathology 69:667-671.

18. Masunaka, A., Ohtani, K., Peever, T. L., Timmer, L. W., Tsuge, T., Yamamoto, M., Yamamoto, H., and Akimitsu, K. 2005. An isolate that is pathogenic to both tangerines and rough lemon and produces two hostselective toxins, ACT- and ACR-toxins. Phytopathology 95:241-247.

19. Masunaka, A., Tanaka, A., Tsuge, T., Peever, T. L., Timmer, L. W., Yamamoto, M., Yamamoto, H., and Akimitsu, K. 2000. Distribution and characterization of $A K T$ homologs in the tangerine pathotype of Alternaria alternata. Phytopathology 90:762-768.

20. Miyamoto, Y., Masunaka, A., Tsuge, T., Yamamoto, M., Ohtani, K., Fukumoto, T., Gomi, K., Peever, T. L., and Akimitsu, K. 2008. Functional analysis of a multicopy host-selective ACT-toxin biosynthesis gene in the tangerine pathotype of Alternaria alternata using RNA silencing. Mol. Plant-Microbe Interact. 21:1591-1599.

21. Nakashima, T., Ueno, T., Fukami, H., Taga, T., Masuda, H., Osaki, K., Otani, H., Kohmoto, K., and Nishimura, S. 1985. Isolation and structure of AK-toxin I and II, host specific phytotoxic metabolites produced by Alternaria alternata Japanese pear pathotype. Agric. Biol. Chem. 49:807815.

22. Nakatsuka, S., Ueda, K., Goto, T., Yamamoto, M., Nishimura, S., and 
Kohmoto, K. 1986. Structure of AF-toxin II, one of the host-specific toxins produced by Alternaria alternata strawberry pathotype. Tetrahedron Lett. 27:2753-2756.

23. Namiki, F., Matsunaga, M., Okuda, M., Inoue, I., Nishi, K., Fujita, Y., and Tsuge, T. 2001. Mutation of an arginine biosynthesis gene causes reduced pathogenicity in Fusarium oxysporum f. sp. melonis. Mol. Plant-Microbe Interact. 14:580-584.

24. Nishimura, S., and Kohmoto, K. 1983. Host-specific toxins and chemical structures from Alternaria species. Annu. Rev. Phytopathol. 21:87-116.

25. Peever, T. L., Canihos, Y., Olsen, L., Ibanez, A., Liu, Y. C., and Timmer, L. W. 1999. Population genetic structure and host specificity of Alternaria spp. causing brown spot of Minneola tangelo and rough lemon in Florida. Phytopathology 89:851-860.

26. Peever, T. L., Ibanez, A., Akimitsu, K., and Timmer, L. W. 2002. Worldwide phylogeography of the citrus brown spot pathogen, Alternaria alternata. Phytopathology 92:794-802.

27. Ruswandi, S., Kitani, K., Akimitsu, K., Tsuge, T., Shiraishi, T., and Yamamoto, M. 2005. Structural analysis of cosmid clone pcAFT-2 carrying AFT10-1 encoding an acyl-CoAdehydrogenase involved in AFtoxin production in the strawberry pathotype of Alternaria alternata. J. Gen. Plant Pathol. 71:107-116.

28. Sambrook, J., Fritsch, E. F., and Maniatis, T. 1989. Molecular Cloning: A Laboratory Manual. 2nd ed. Cold Spring Harbor Laboratory, Cold Spring
Harbor, NY.

29. Sanger, F., Nicklen, S., and Couldon, A. R. 1977. DNA sequencing with chain-terminating inhibitors. Proc. Natl. Acad. Sci. USA 74:5463-5467.

30. Scheffer, R. P., and Livingston, R. S. 1984. Host-selective toxins and their role in plant diseases. Science 223:17-21.

31. Tanaka, A., Shiotani, H., Yamamoto, M., and Tsuge, T. 1999. Insertional mutagenesis and cloning of the genes required for biosynthesis of the host-specific AK-toxin in the Japanese pear pathotype of Alternaria alternata. Mol. Plant-Microbe Interact. 12:691-702.

32. Tanaka, A., and Tsuge, T. 2000. Structural and functional complexity of the genomic region controlling AK-toxin biosynthesis and pathogenicity in the Japanese pear pathotype of Alternaria alternata. Mol. PlantMicrobe Interact. 13:975-986.

33. VanEtten, H. D., Jorgensen, S., Enkerli, J., and Covert, S. F. 1998. Inducing the loss of conditionally dispensable chromosomes in Nectria haematococca during vegetative growth. Curr. Genet. 33:299-303.

34. Walton, J. D. 1996. Host-selective toxins: Agents of compatibility. Plant Cell 8:1723-1733.

35. Wolpert, T. J., Dunkle, L. D., and Ciuffetti, L. M. 2003. Host-selective toxins and avirulence determinants: What's in a name? Annu. Rev. Phytopathol. 40:251-285.

36. Yoder, O. C. 1980. Toxins in pathogenesis. Annu. Rev. Phytopathol. 18:103-129. 